\title{
Cognition, technology, and work: special issue on cognitive ergonomics for designing collaborative activities
}

\author{
Anke Dittmar $\cdot$ Peter Forbrig
}

Published online: 19 July 2012

(C) Springer-Verlag London Limited 2012

\section{Introduction to the special issue}

This special issue presents six papers organized by the theme: "Cognitive Ergonomics for Designing Collaborative Activities". Originally, the focus of cognitive ergonomics has been on the performance of single users, on understanding their cognitive abilities, needs and preferences while interacting with machines and computers. Human activities are inherently collaborative, though, and in the past two decades, the field has gradually broadened its perspective on the analysis and the design of work systems, tasks and supporting technology. It is common ground now that designing for use requires a deep understanding of collaborative aspects and of appropriation processes of artefacts in complex social settings. The special issue on collaboration in context: cognitive and organizational artefacts, published by Cognition, Technology and Work in 2005 (Jones et al. 2005) is an example of reflecting this development that was supported by close interaction with other disciplines such as human-computer interaction (HCI), cognitive psychology, information science, sociology and organizational sciences. The mutual exchange of knowledge and ideas is also visible in the contributions of this issue.

Design interventions inevitably change work practices as artefacts shape cognition and collaboration (Woods 1998). New tools, representations or organizational structures make some of the existing obsolete and require an adaptation of skills and knowledge. Their appropriation not

\footnotetext{
A. Dittmar $(\bowtie) \cdot$ P. Forbrig

Rostock, Germany

e-mail: anke.dittmar@uni-rostock.de

P. Forbrig

e-mail: peter.forbrig@uni-rostock.de
}

only changes forms of collaboration but also-at a deeper level-relationships between the participants (e.g. power relations). The effects of design activities, whether they are intended or not, need to be reflected within the particular problem setting and at a more general level to improve the design understanding for the future. The theme of this special issue is not new, but it requires ongoing attention. The current issue provides studies that contribute to a more detailed picture of the diverse forms of human activities and how they are or could be mediated by technology. It is mainly a selection of extended versions of papers presented at the European Conference on Cognitive Ergonomics 2011 which went through an additional reviewing process to be accepted for this special issue.

\section{Design scope}

The contributions of this special issue cover a broad array of collaborative settings ranging from critical information infrastructures such as communication networks (Norros et al. 2012) to scientific work (Vyas 2012) to everyday use of technology Turner and Turner (2012). "[T]he workplace has ceased to be the exclusive focus of design", comment Crabtree et al. on the dramatic expansion of the design scope that can currently be observed in our society. "The digital, like a host of technologies before it, is permeating society at large. The contemporary challenge for design is to better understand how the computer in all its forms may be developed to support activities in a broad range of nonwork settings" (Crabtree et al. 2009). Every environment has its specificities. The applicability of prior design knowledge to a new domain needs to be carefully investigated as shown in this issue by Grönvall and Kyng (2012) for the use of rehabilitation technologies in elderly peoples' 
own homes or by (Vyas et al. 2012) for design studios, a less-explored "work setting". However, the expansion of technology use to "non-work settings" has an impact on the way people cooperate at work. In this issue, Détienne et al. (2012) explore Second Life meetings in educational and professional settings. This expansion may change the design understanding in more traditional application domains for cognitive ergonomics. To give one example, it is assumed in the study by Grönvall and Kyng (2012) that the elderly people-as users of the system-cannot be blamed for a system failure. Performance and productivity are not design goals with highest priority, but the diverse nature of homes and the people's personal taste have to be respected. Such explicit assumptions may support, in turn, a reflection of design decisions made in professional domains.

\section{Underlying conceptions of collaboration and artefact use}

In this issue, Norros et al. (2012) discuss different ways to study the human operators' work in communication networks. While some approaches focus on the individuals' problem solving and decision-making in specific tasks or on human error, other approaches try to understand daily cognitive work demands. Yet other approaches take a more system-oriented and holistic view on the dependability of network infrastructures. Building upon work by (van Eeten et al. 2006) and others (Norros et al. 2012) aim to understand which resources and sense-making skills network operators have developed to act in their dynamic, complex and uncertain environments. Research activities, like any other human activities, are guided by underlying conceptions of the objects of interest. All six papers reflect a perspective on collaborative work and the role of artefacts in supporting it that goes beyond a "mere" cognitive approach. As a second example, the work on design studio practices presented by (Vyas et al. 2012) is based on a deep acknowledgement of the importance of material artefacts and the physical workspace for the communication and the collaboration between co-designers. It is influenced by ideas coming from distributed cognition, Schön's view of design as reflective conversation with the materials of the design situation (Schön 1983) and others.

Grönvall and Kyng (2012) as well as Turner and Turner (2012) discuss forms of collaboration that are less explored in the context of cognitive ergonomics. Grönvall and Kyng's approach to design home-based healthcare systems is rooted in the Scandinavian participative design movement where participants are seen "as competent actors with skill sets that could be augmented via various forms of computer applications (tools)" (Bannon 2011). Throughout the design process, the participants' situations, interests and motivation are considered more explicitly to facilitate negotiation. The authors explore how these assumptions help to design with and for ill or other less resourceful users. Susan and Phil Turner's investigation of everyday use of digital technology is guided by the concept of attachment and the related themes of appropriation, commodities versus things and singularization of Kleine and Baker (2004). Their approach allows us to extend the consideration of artefact use to emotional and social aspects. A deeper understanding of peoples' attachment to (digital) artefacts is important, for example, for tackling the challenges in sustainable design. Are digital artefacts rather seen as commodities delivered and easily thrown away or as things of value facilitating adaptation and participation? Artefacts shape cognition and collaboration-and resources for future generations.

\section{Building theoretical knowledge}

In his article, Vyas points out that practices in the analysed domain evolve and change over time. Woods considers investigations and design interventions into ongoing working practices as an essential prerequisite for advancing our understanding of the relationship between technology change and cognition/collaboration. "Fields of practice are applications, but also function as natural laboratories". The challenge is to use the particular design intervention as a tool "to derive general lessons about cognition and collaboration" and to build theoretical knowledge (Woods 1998). Four of the six papers present design-oriented studies in domains where technological artefacts have been used over a longer period of time. Field observation methods were applied to analyse and describe emergent collaborative behaviour and work demands as well as implications for (re-)design. The contributions in this special issue also increase our knowledge about design processes and about relevant design concepts. The following section gives an overview of the articles and achieved research results.

\section{Summary of papers}

The first two papers analyse collaborative work in domains with complex tasks and high-tech support. Both studies acknowledge the increasing role of (tool-supported) sensemaking processes. In "Impact of Human Operators on Communication Network Dependability", a case study in a large telecommunication company is presented. Network dependability is significantly influenced by human operators. Norros and colleagues conducted interviews to 
understand the operators' conception of their work and their ways of acting to provide high availability of the network in an environment with daily changes to the network and continuous increase of its complexity. One result of the analysis is the definition of domain-specific control requirements and constraints on the basis of three dimensions (dynamicity, complexity and uncertainty) that characterize demanding monitoring and control tasks in unexpected situations. By relating these control requirements and available psychological resources (skills, knowledge and collaborative resources), core-task demands were identified and categorized. The operators' actual courses of action are framed by these demands. The authors conclude that a better balance between proactive and resilient methods is needed in communication network operation work to cope with unexpected events. This can be achieved by a shift of resources from long-term planning (anticipation) to real-time management (resilience). The second paper, "Ethnographic Notes on Visualization Practices in Tissue Engineering Research", explores visualization practices of life scientists in the domain of tissue engineering. Vyas observed laboratory experiments, reasoning processes and collaborative practices. He shows that the scientists create and interact with different biological objects and tools throughout the whole culturing process. Their understanding of cell structures is not a pure rational activity but requires longtime engagement with the physical material and a continual transformation of cell structures and models. Life scientists use craftwork, creativity and their own embodied knowledge to enhance their scientific reasoning. Their collaboration is supported by different forms of visual objects.

The next two papers present studies in non-professional settings. Grönvall and Kyng's contribution in "On Participatory design of home-based healthcare" is twofold: first, they explain the specifics of home environments as design spaces. Second, they explore influences of their design approach on design interventions. The theoretical work is grounded in a participatory design (PD) project to support daily home-based rehabilitation practice for elderly people. The authors describe how initial project ideas were changed by the participants' growing understanding of homes as unique and complex environments that cannot be controlled in the same way as hospital settings. Design solutions for assistive technologies have to consider, for example, decorative values and mobility (people have summer houses, they travel and so on). Four challenges in transferring experiences from work-based PD to homebased PD were identified: (1) designing for, and negotiating knowledge about the home, (2) how to include ill, weak users in the PD process, (3) divergent interests of participants, 4) usable and sustainable post-project solutions.
In their paper, Grönvall and Kyng mention a less visible form of cooperation that is based on a feeling of responsibility some patients may have developed for future patients. One motivation for them to take part in the described project was to support research and to help future patients. Susan and Phil Turner's work on material attachment and related concepts contributes to the research on long-term user experience and sustainability. In "Emotional and Aesthetic Attachment to Digital Artefacts", differences in peoples' attachment to digital and non-digital artefacts at the personal level are examined. The authors use Borgmann's distinction between things (meaningful, socially inscribed) and commodities (mass produced, context-free) to discuss the nature of digital artefacts. They point out that material attachment develops over time and encourages people to preserve an object. It becomes a thing, maybe even worth to be passed on to the next generation. In order to understand an individual's orientation to technology, the repertory grids technique was applied in two studies. Turner and Turner found out that people are attached to digital and non-digital artefacts in indistinguishable ways. There is a clear evidence of appropriation, de-commodification and sense of ownership in both cases. These results challenge current findings (e.g. in the field of Sustainable Interaction Design) indicating a weaker attachment to digital artefacts. Another interesting result of the study suggests that individuals are emotionally and aesthetically attached to artefacts with physical proximity.

Vyas, van der Veer and Nijholt, in the fifth paper, "Creative Practices in the Design Studio Culture: Collaboration and Communication", present an ethnomethodologically informed field study in professional and academic product design studios. Their focus is on understanding material and physical aspects that support creativity in the designers' everyday work. The authors draw on work from CSCW literature about the role of materiality in supporting cooperative work. The paper discusses the collected field material along three broad themes: use of artefacts, use of space and designerly practices. The results give insights into the explorative practices of design practitioners, characterized by the creation and use of a wide variety of material artefacts for diverse purposes. It is shown how designers use and adapt their physical workspace to have these artefacts ready-to-hand. The paper concludes with design implications and a discussion of new technologies that can be used to support the inherent embodied and ubiquitous nature of work in design studios.

Finally, in "Interactive frames constructed in Second Life meetings: a study in educational and professional settings" Détienne and colleagues aim to understand new types of communicative behaviour that develop by using new collaborative technologies. Four Second Life (SL) 
meetings in educational and professional settings were analysed on the basis of two complementary theoretical approaches to understand interaction: interpretative and participation frames and interactive roles. In order to understand not only the use of SL but also meanings constructed by participants in certain situations of a meeting, the authors used observational data to develop a third view perspective as well as interview data to develop a first view perspective. This is an original contribution. The paper discusses boundaries between serious and recreational registers, spatial positioning as indicators and constructors of roles and engagement, management of communication fluidity and joint focus and other points. The results of the study show the specifics of each meeting, but also similarities between analysed meetings concerning frames, interactive roles and used communication media. For example, the speaker tended to restrict their use of different media in all meetings when the focus was on task content. However, a wide range of media was used when the focus was on the process (e.g. voice, chat, gestures).

Acknowledgments Besides the authors that submitted to this special issue, we gratefully thank the reviewers Liam Bannon, David Benyon, Willem-Paul Brinkman, Jonas Lundberg, Thierry Morineau, Leena Norros, Hanna Toivianen, Phil Turner, Herre Van Oostendorp and Fulko van Westrenen for their critics, hints and helpful comments. We also warmly acknowledge Carlo Cacciabue for his advice and guidance.

\section{References}

Bannon L (2011) Reimagining HCI: toward a more human-centered perspective. Interactions 18(4):50-57
Crabtree A, Rodden T, Tolmie P, Button G (2009) Ethnography considered harmful. In: Proceedings of CHI'2009. ACM Press, pp 889-898

Détienne F, Cahour B, Legout M-C, Gourvennec B, Relieu M, Coppin G (2012) Interactive frames constructed in Second Life meetings: a study in educational and professional settings. Cogn Tech Work. doi:10.1007/s10111-012-0230-y

Grönvall E, Kyng M (2012) On participatory design of home-based healthcare. Cogn Tech Work. doi:10.1007/s10111-012-0226-7

Jones PH, Chisalita C, Veer GCVD (eds) (2005) Cognition, technology, and work: special issue on collaboration in context: cognitive and organizational artefacts. Cogn Technol Work 7

Kleine SS, Baker SM (2004) An integrative review of material possession attachment. Academy of marketing science review, 1. Available from http://www.uwyo.edu/mgtmkt/faculty-staff/ faculty-pages/docs/baker/materialpossessionattachment.pdf. Last retrieved 17 June 2012

Norros L, Norros 1, Liinasuo M, Seppänen K (2012) Impact of human operators on communication network dependability. Cogn Tech Work. doi:10.1007/s10111-012-0225-8

Schön D (1983) The reflective practitioner. How professionals think in action. Temple Smith, London

Turner P, Turner S (2012) Emotional and aesthetic attachment to digital artefacts. Cogn Tech Work. doi:10.1007/s10111-012-0231-x

van Eeten MJG, Roe D, Schulman PR, de Bruijne M (2006) The enemy within: system complexity and organizational surprises. In: Dunn M, Mauer W (eds) International CIIP handbook, vol II. Center for Security Studies, ETH Zürich, Zürich, pp 89-110

Vyas D (2012) Ethnographic notes on visualization practices in tissue engineering research. Cogn Tech Work. doi:10.1007/s10111012-0238-3

Vyas D, van der Veer G, Nijholt A (2012) Creative practices in the design studio culture: collaboration and communication. Cogn Tech Work. doi:10.1007/s10111-012-0232-9

Woods D (1998) Designs are hypotheses about how artifacts shape cognition and collaboration. Ergonomics 41:168-173 